\title{
Sustainable Industrial Transformation: For whom and where to start?
}

\author{
ANABELLA \\ ROSEMBERG
}

\begin{abstract}
Climate change and the need to shift to low-carbon societies require a massive transformation in how economies and industries function. This article outlines a framework for achieving sustainable industrial transformation in pursuit of fulfilling the Paris Climate Agreement and the Agenda 2030 for Sustainable Development, with a focus on the impact on workers. At the core of this transformation is the Just Transition for workers which aims at setting the right policy goals across environmental, social and economic pillars and securing public support for achieving a zerocarbon, zero-poverty future.
\end{abstract}

KEYWORDS just transition; labour market policies; climate change; rights at work; social protection

\section{Introduction}

With the historical decisions of 2015 by government leaders to adopt the UN Sustainability Goals and the Paris Climate Agreement, a zero-carbon, zero-poverty world is within our reach. But it will require universal sectoral and economic transformations on a scale and at a speed faster than any in human history. These transformations must be based on the principles of a Just Transition, which ensures no one is left behind.

All countries around the world face major challenges, among them climate change, inequality and unemployment. Until now these challenges have often been confronted in isolation and even, at times, in competition. Underpinning these challenges there is the growing impression that the space for an economy to create high quality, productive jobs is shrinking.

Global supply chains have grown to the point where hardly any country is disconnected from them. Despite this it is hard to realize benefits for working people, even in developed countries. Most of these companies have made the choice of reducing their investment in innovation and long-term sustainability to prioritize short-term shareholder benefits. This is impacting on wages, employment and making work more precarious, while also having detrimental effects on the environment. Companies are 'externalizing' bad social and environmental impacts and asking the public to pay for them all while absorbing vast amounts of wealth often redirected 


\section{Rosemberg: Sustainable Industrial Transformation}

through complex operations to tax havens. In developing countries, the impact is even more pronounced. As the ITUC 'Scandal' report signals, '(...) profits are too often driven by low-wage levels that people cannot live on, risking safety with the result of indefensible workplace injuries and deaths, increasing tax evasion or tragically linked to pollution of community land and water. (...) The wealth generated by workers is not being shared with them. Increasing numbers of workers are trapped in the hidden workforces of the richest companies in the world. They have no job security and work long hours for poverty wages in unsafe environments or with unsafe products' (ITUC, 2016).

This assessment is shared by a variety of actors that go well beyond the traditional left to include analysts from the 'mainstream' of economic thinking, and many important questions arise. What are the policies that can sustainably address inequalities, unemployment, climate change and environmental degradation? What is the role of the State? Beyond short-term actions, can there also be convergence in the medium- to long-run in terms of the reforms all our economic sectors must undertake to respond to these overlapping crises?

However, when it comes to responding to these questions, there remains fundamental divergence. It is important to state that the current trends in the public debate are far from presenting a long-term solution.

Governments are asked to react to a multipronged crisis, and addressing the future of production and services is central, but solutions must maintain the capacity for future generations to live in dignity. Sustainable industrial transformation must therefore be seen in this context, and its success be assessed against its capacity to respond coherently to these challenges.

\section{Short-term positive impacts of environmental policies}

Sustainable industrial transformation is a longterm endeavour. However, and perhaps counterintuitively, setting ambitious short-term policies targeting specific sectors' transformation can be a driver of long-term change while at the same time spurring job growth and economic activity in the short run. In order to have a chance of staying within the $2{ }^{\circ} \mathrm{C}$ limit and even more when it comes to the $1.5{ }^{\circ} \mathrm{C}$ limit, our balance of emissions should reach zero by mid-century. The urgent need to reduce greenhouse gas emissions highlights the importance of setting coherent climate and investment goals, which can also mean job-growth policies.

The industries of today are the foundations for the industries of tomorrow, and the next 15 years will be critical. There are substantial opportunities for job creation, but there are also great challenges.

Investment in infrastructure by 2030 is predicted to be up to USD 90 trillion. With infrastructure requirements in transport, energy, water systems and buildings, just to mention a few sectors, this could be up to USD 7 trillion dollars per year on average over the next 15 years. This will mean job growth, and if properly designed, it will also mean better quality of living for the population and a cleaner environment.

A 2010 study by the Millennium Institute for the ITUC showed that if just twelve countries invested 2 percent of GDP each year for five years in major sectors (energy, transport, manufacturing, agriculture and construction) through sustainable policies (renewable energy, energy efficiency, organic agriculture, sustainable water management and public transit), this could generate around 48 million jobs.

The ILO has also found that most studies show a positive net employment effect of policies facilitating climate transition. Net gains are up to 60 million jobs, combining economic growth with environmental improvement.

Outside urban areas, agriculture and forestry hold the key to feeding the world's people and sustaining the natural environment, resulting in further job creation.

Policies aimed at 'greening' jobs are also critical. By reducing the environmental impact of all sectors and working towards providing better working conditions, these policies prepare the ground for medium-term industrial change. 
In this context, 'greening' should be understood as the actions taken to improve the environmental and social performance of jobs across sectors, whether they are considered today as 'green' or not. The case of the construction sector is particularly telling. Neither 'green' nor 'black', this sector is critical for growing jobs in a sustainable economy, but often the quality of those jobs on offer does not make it an attractive sector for many. Training on energy efficiency, for example, by raising the level of workers' qualifications, provides them with tools to access better-paid jobs. That said, we have also seen that when it comes to working conditions (wages, rights at work, occupational safety and health) much needs still to be done to ensure 'green'/'greener' jobs build a bridge towards a fairer economy.

This requires an appropriate policy mix to ensure better working conditions lead to combatting inequality and to signal to people the positive potential these new jobs can represent for them.

\section{Sustainable industrial transformation: objectives and contribution}

Despite the long-term impact of short-term measures, it goes without saying that sustainable industrial transformation must also aim much further. It must contribute to tackling, in the long-run, the multiple deficiencies of our current economic model, addressing the challenges described in the following section at their root.

\section{The security challenge}

Overwhelming shifts towards precarious forms of employment-short-term contracts, hidden employment relationships through self-employment arrangements, part-time and seasonal work, coupled with a historical low in the share of wages in GDP, which shows that the wealth created by workers is not being redirected to them-are all a major source of insecurity. When we add to this the fact that 75 percent of the world's people have no, or inadequate, social protection and even in developed economies austerity policies have left millions vulnerable, the result is both fear and an inability to participate in an already stagnant economy. It is clear then that economic transformation must ensure people can move from survival to living dignified lives. Coupling good quality jobs with strong social protection coverage is therefore one of the main challenges of the transformation. Ideas being explored and tested at the local level, such as a guaranteed minimum income, need to be considered seriously, as they can provide a security cushion that supports every citizen's capacity to be an actor in their community.

\section{The sobriety challenge}

We must secure dignity without impacting future generations' capacity to secure theirs. Climate change and toxic pollution are clear examples of our generation adding a huge burden to future generations. There is an urgent need to get to zero emissions, to reduce resource use and re-use what we can, to dramatically change the energy mix to move into renewable energies, to implement a life-cycle approach to products and to better integrate environmental benefits and costs in production and consumption to protect and, where possible, restore ecosystems. It is also important to re-think the economy around the satisfaction of needs rather than the capacity to buy goods (for example promoting mobility services with multiple options, rather than buying one car per household).

\section{The 'sharing' challenge}

Economic inequality has become a threat to the global economy and to the lives of millions of people worldwide. Re-distribution of wealth and of income in particular is urgently needed both among and within countries. This requires the elimination of tax heavens and tax evasion strategies, and avoiding speculation and price bubbles which lead to drastic price fluctuations that further harm the economy. We need serious efforts to ensure that wealth created by corporations, sustained by public investments in infrastructure, education, health and security are brought back to the system through fair taxation policies. Better 


\section{Rosemberg: Sustainable Industrial Transformation}

wealth distribution also goes hand in hand with redistribution of power. Democracy, people's participation in decision-making, respect for human rights and the rule of law must also be part of the transformation. The need to build stronger democratic institutions for driving our economy is also a key parameter for guiding the industrial transformation we need.

A sustainable industrial transformation can contribute to achieving these goals by stimulating innovation and profound changes in technologies and processes, by raising resource productivity and recycling the benefits into wages and working conditions, reconnecting workplaces with communities, re-establishing a closer loop in terms of production and services and revitalizing local employment, among others. In countries trapped by low-wage, low-skilled, highly polluting supply chains, industrial transformation allows a whole-economy thinking and opens opportunities for a different integration into those supply chains.

\section{Scale, target and process}

Achieving long-term goals is accompanied by a series of challenges, and different currents of thought have diverse views on the role the State should play in trying to stimulate sectoral changes in their economies. That said, researchers see a 'rapprochement' between thinkers: 'discussion among economists and policy makers is now increasingly shifting away from whether to have industrial policy and more towards a focus on the objectives and scope of industrial policies and "how to do it" in a way appropriate to each country's conditions' (Salazar-Xirinachs et al., 2014).

\section{At a minimum: set the right targets, prevent wrong from continuing}

Giving the country a direction by setting key goals in terms of the challenges mentioned above, without ignoring any of them, is fundamental to steer change and give clear guidance on the way forward. Confusing signals in terms of governmental commitment to renewable energies' deployment, or in terms of achieving decent work for all, sends companies the signal that their investments do not need to be attached to those public goals.

The Sustainable Development Goals provide for the first time an integrated list of goals, objectives and soon indicators which can serve as markers for coherent industrial transformation in a country.

Sometimes the easiest decision taken by governments is to support policies that prevent any unrest, including adopting contradicting measures (support a strong renewable energy price while at the same time subsidizing fossil fuels; deploy social protection measures while raising VAT; and the list goes on). So, at a minimum, governments need to set the right targets and avoid directing public resources to policies which contradict long-term goals. Of course, this is easier to say than to do, as every public policy generates its beneficiaries and it is normal that modifying the rules challenges the status quo. Assessing how vulnerable populations would be supported in a period of change is key for sustaining social support.

\section{Targeted support}

Targeted interventions to provide public support, i.e. subsidy for those increasing efforts to recycle materials in production units, market interventions that support specific sectoral constraints (i.e. putting in place a feed-in tariff for renewable energy generation), promotion of learning and skills development in sectors of benefit for attaining goals, among others, are part of the menu of options available for a government willing to support sectoral changes.

\section{Partnership with leaders, sticks for the laggards}

The relationship with companies in this process is far from being straightforward. From business leaders that understand the necessity to change their business model to those deploying incredible efforts to block any progress, there is a huge diversity, so any policy responses by public authorities need to address that diversity. 543 


\section{Development 58(4): Dialogue}

Sustainable industrial transformation requires public authorities to support those engaging in innovation, research and engaging with the employees in planning a transition for their company. It also requires setting floors for the laggards which are accompanied by obligations and penalties for underperformance.

\section{Innovation, technology and intellectual property}

Sustainable industrial transformation also requires progress on the innovation and technology dimension. In addition to the regulatory framework which can steer innovation, there are other aspects that today prevent the massive deployment of technologies, such as intellectual property rights associated with patents, trade secrets and copyright, slowing down progress in some sectors.

In its Frontlines report, the ITUC suggested: 'This problem could be solved in a number of ways - for example by establishing a worldwide licence pool that guarantees universal access to technologies. This could be achieved through global initiatives where licences were purchased (for example, by the UN) and then made available to countries that could otherwise not afford them. The money needed for licence purchasing could be taken from carbon pricing revenues or from a global climate fund. However practical the demand to share technologies, if not globally negotiated, and considering demands for equity, it may be a struggle similar to that undertaken to gain access to generic medicines' (ITUC, 2015).

\section{Where to start: a Just Transition framework}

All these goals, and the policies defined to attain them, imply important changes in the world of work. So important are those changes that some might be tempted to use those challenges to delay action (either because they are truly worried or because it is simply convenient as an excuse). 544 However, the impacts of inaction on inequalities, jobs or the environment would be catastrophic for our economies and for the likelihood to live in dignity as humanity.

The idea that we can cooperate and plan a transformation of our economic sectors in a way that they tackle today's challenges in a coherent fashion might not be new, but the notion to do so through a based-on-experience policy package is. It is what the labour movement has been calling a Just Transition and has now been adopted by other community and NGO groups, UN agencies and governments, among others.

The Just Transition framework is a package of policy proposals which addresses the different aspects related to the vulnerability of workers and their communities: uncertainties regarding job impacts, risks of job losses, risks of undemocratic decision-making processes, risks of regional or local economic downturn, among others. If certainly not a full package for securing sustainable industrial transformation, it is certainly the key for setting the right policy goals and securing public support for the transformation.

\section{Support the re-direction of investments towards low-emission and labour-intensive technologies and sectors}

The transformation we need to achieve is one that must not focus on our capacity to retain industries but rather to ensure that those industries re-align their business model with a zeroemission world. This goes beyond avoiding emissions at plant level to challenge the very way in which operations are organized and products are conceived. This is a massive opportunity for creating local jobs with high skills-content, supporting innovation and re-localizing jobs. However, without a substantial shift in investment towards these sectors, those opportunities will not be realized and will hinder progress on climate and employment objectives. Workers from declining sectors or young workers who have not yet entered the labour market need job alternatives, and 'green' investments can provide them. These investments could be driven, in the initial phase, by public sector policies, including procurement, infrastructure projects and public regulations. 


\section{Rosemberg: Sustainable Industrial Transformation}

Social dialogue and democratic consultation of social partners and stakeholders

Governments should consult with and encourage institutionalized and formal involvement of trade unions, employers, communities and all other relevant community groups. Consultation and respect for human and labour rights form the baseline conditions for a smooth and effective transition towards a sustainable society.

Social dialogue is not only important at the national level. Companies today face the need to plan for a different future and must do so in cooperation with their unions and employees. A consensual plan about how to achieve a zerocarbon footprint is the best way to achieve it in the shortest timelines.

\section{Research and early assessment of social and employment impacts}

A proper consultation process will not be sufficient unless it is accompanied by relevant studies assessing the impacts of sustainability policies on production systems. Systematic country, regionand sector-specific studies on climate change policies and their impacts on employment and labour markets must be carried out.

\section{Training and skills development}

Changes on the ground require workers to be trained in clean processes and technologies. This is key to absorb and develop new technologies and to realize the potential of 'green' investments. Educational leave for workers to acquire new skills might be needed. Promoting skills' development is one of the dimensions to be developed hand in hand with investments, regulations and other engines of industrial policy.

\section{Social protection and active labour market policies}

Vulnerability may be a source of reluctance to support change. Social protection schemes, including active labour market policies, are key to ensuring justice during the transition. A certain number of policies will need to be promoted to avert or minimize job losses, to provide income support and to improve the employability of workers in sensitive sectors. Some critical elements include the need to secure pensions and other social security provisions, put in place social insurance and when needed public employment guarantee schemes, job-creating public works programmes for the unemployed and working poor, and income maintenance and job placement services, among others. Social protection systems, acting as a driver for wealth distribution, also contribute to a sustainable industrial transformation done in cooperation with all citizens, and not marginalizing those who were part of the previous model.

\section{Community/territorial economic diversification plans}

Sustainable industrial transformation is first and foremost a community need. Each region and community must be in the position to integrate a new economic model. In many cases this will require starting as soon as possible with economic diversification plans. Communities cannot be abandoned to situations of ultimate rescue, as that does not lead to a fair distribution of costs and benefits.

\section{Diversifying Just Transition strategies}

The elements described in the section above, while broad and general, represent a stepping stone for building a successful industrial transformation of our economies, as they cover a variety of measures while putting at the heart the need to address, along with employment, the need for social justice and environmental protection. Although all those policy options have been tested and proven successful in various contexts, no single country has yet organized the fundamental transformation that the Just Transition framework calls for.

The complex reality that different countries and regions are going to face in their transitions to a socially fair, jobs-rich, zero-carbon and climate-resilient economy requires the Just 


\section{Development 58(4): Dialogue}

Transition concept to be developed considering at least three different starting points and consequent policy options.

\section{Carbon-intensive, increasingly unequal, developed countries}

These countries are resource-intensive and relatively wealthy. Their per capita consumption rates would exceed the planet's ecological limits if they were reproduced globally. In their case, a deep transformation of production and consumption patterns is needed. The movement towards highly efficient and zero-carbon patterns can be done without harming the prosperity of all their inhabitants.

Most of the countries in this group are facing a severe economic crisis, with high unemployment rates. If the political choice has been to orient the economic response to budgetary cuts and marginal intervention in the productive system, an alternative exists-one which will put the transition agenda at its heart. To drive changes in recovery, inequality reduction and climate soundness, a timeless agenda is required, one that has effected recovery in previous decades, with provisions to cushion the negative effects of changes in labour markets on workers-unemployment benefits, training and skills development and job placement services. Today many such policies are under attack, undermining even further the capacity to organize the transition (Table 1 ).

\section{Increasingly carbon-intensive, unequal emerging economies}

With their increased share of international production and trade, emerging economies seem to follow development pathways like those of

Table 1.

Driving investments

Put a price to GHG emissions through regulations

Incorporate 'green' investments into recovery plans

Mainstream climate change needs in public procurement

Develop 'green' fiscal policies (incorporating environmental protection while preserving the long-term sustainability of the system and pensions in particular)

Reform corporate governance (shift from shareholder to stakeholder-driven decision-

making)

Identify priority regions and use investments to prepare their future

Social dialogue

Adapt social dialogue institutions and promote a workers' right to know how their

companies will reach a zero-carbon target

Consider developing tripartite dialogue at the sectoral and territorial level for planning the transition

Promote multi-stakeholder platforms

Skills and training

Update training schemes to incorporate 'green-economy' needs

Mainstream lifelong learning in workers' careers

Upscale the profile of technical careers

Social protection

Stop undermining social security systems and provisions to sustain income in periods of unemployment

Ensure pension security for all those facing structural change in their sectors

Develop protection schemes adapted to scattered careers

Accompany workers and SMEs in declining sectors with programmes of entrepreneurship 
Table 2.

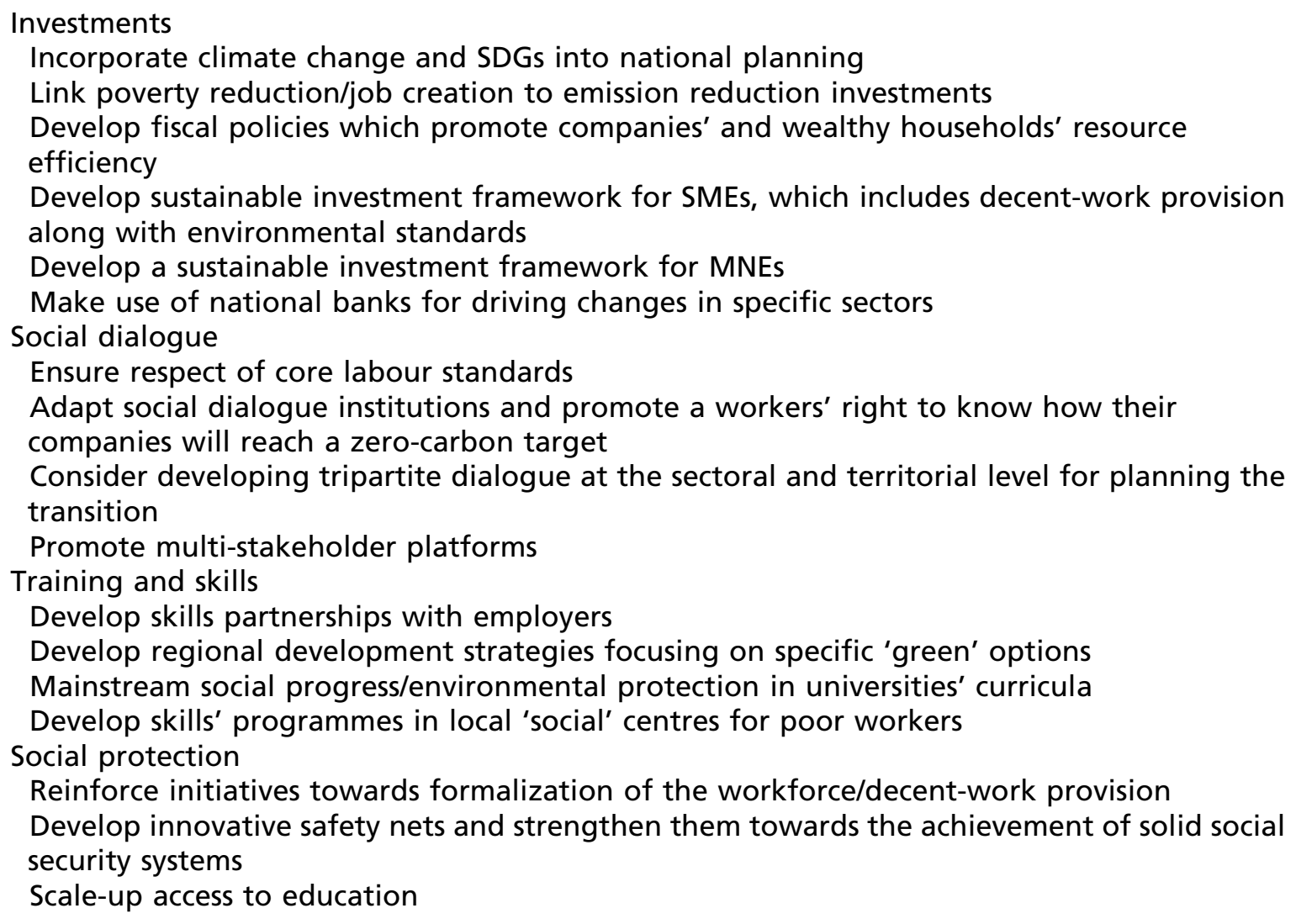

industrialized countries. This development model leaves social inequalities and environmental protection to be addressed at a later stage, once sufficient wealth has been created. This idea, which might have 'worked' for industrialized countries, seems difficult to realize now. Several environmental challenges are reaching their tipping points, and social unrest is increasing. People might not wait generations for the distribution of wealth to occur, nor to enjoy a healthy environment. A Just Transition strategy in these countries implies an earlier and different implementation of social and environmental policies than that of developed countries.

It would include a better integration of environmental and fairness concerns in development planning, the promotion of an original economic model and the development of innovative social protection schemes (Table 2).
Low-carbon, highly climate-vulnerable, poor yet the most unequal, developing countries

The capacity of developing countries to deliver a Just Transition programme is modest. However, as part of their strategies to diversify their economies and ensure their citizens attain dignified conditions of life, there are opportunities for this framework to contribute to a sustainable industrial transformation (or rather sustainable industrial development). Exploring the means to mainstream climate change in development aid, to expand democratic decision-making on these issues, to fight unemployment, informal work and corruption, among others, seems fundamental. A Just Transition strategy in these countries also requires respecting trade union rights to ensure that workers' voices are heard during the transition (Table 3). 


\section{Development 58(4): Dialogue}

Table 3.

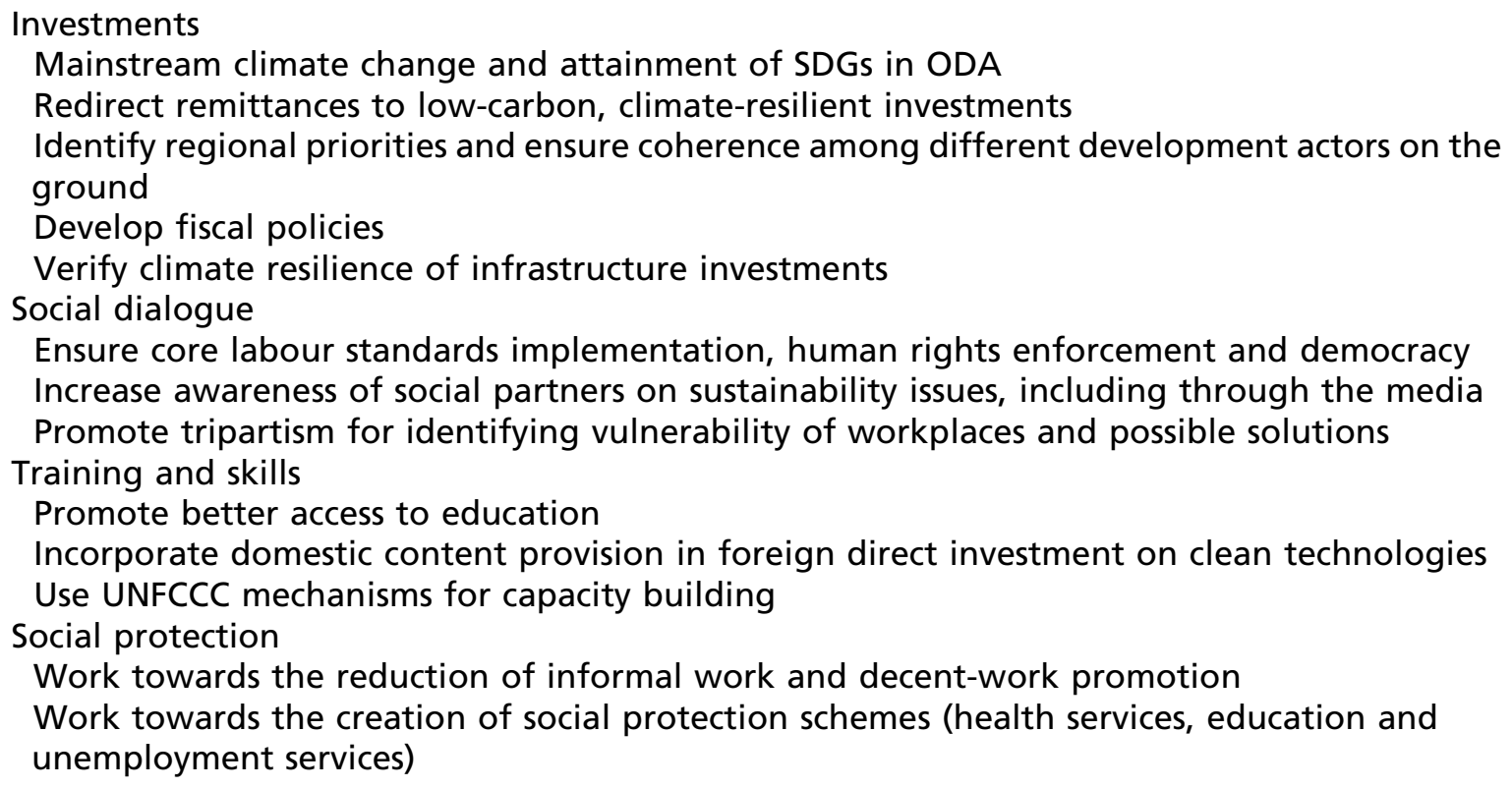

\section{Conclusion}

Sustainable industrial transformation is not a single, straightforward process. Rather, it needs to be a democratic, forward looking and collective endeavour, built in close cooperation with all relevant stakeholders. Its success depends very much on its goals, the coherence of policy measures taken to achieve them and public support through community engagement. Decent-work, fairness and zero-carbon economies are the imperative and central to the attainment of the SDGs. It is time to put these ideas to work.

\section{Acknowledgements}

This article has benefitted from substantial comments provided by Sharan Burrow and Matt Simonds.

\section{References}

ITUC (2015) 'No Jobs on a Dead Planet', Frontlines Report, International Trade Union Confederation.

ITUC (2016) 'Scandal-Inside the global supply chains of 50 top companies', Frontlines Report 2016, Brussels, Belgium: International Trade Union Confederation.

Salazar-Xirinachs, José Manuel, Irmgard Nübler and Richard Kozul-Wright (eds.) (2014) Transforming economies: Making industrial policy work for growth, jobs and development, Geneva: International Labour Office. 